Full Length Article

\title{
Thermophysical behavior of three algal biodiesels over wide ranges of pressure and temperature
}

\author{
D. Bessières ${ }^{\mathrm{a}, *}$, J.-P. Bazile ${ }^{\mathrm{a}}$, X. Nguyen Thi Tanh ${ }^{\mathrm{b}}$, F. García-Cuadra ${ }^{\mathrm{c}}$, F.G. Acien ${ }^{\mathrm{c}}$ \\ ${ }^{a}$ Laboratoire des Fluides Complexes et Leurs Réservoirs, UMR5150, CNRS-TOTAL, Avenue de l'Université, 64013 PAU Cedex, France \\ ${ }^{\mathrm{b}}$ Chemical Engineering Faculty, The University of Danang - University of Science and Technology, Danang, Viet Nam \\ ${ }^{\mathrm{c}}$ Dpt. Chemical Engineering, University of Almeria, 04120 Almeria Spain
}

\section{A R T I C L E I N F O}

\section{Keywords:}

Biodiesel

Microalgae

Cyanobacteria

Density

Viscosity

\begin{abstract}
A B S T R A C T
The knowledge of density and viscosity is important both for the optimization of diesel engines operation and the fuel quality specification. To this end, the present work focuses on the study of these thermophysical properties for three algal biodiesels. The samples were produced by transesterification of dry biomass supplied from different microorganisms, the marine strain Nannochloropsis gaditana, the freshwater strain Scenedesmus almeriensis and the freshwater cyanobacteria Spirulina platensis. The protocol of production is detailed. The purity of biodiesels is low, ranging from $63,7 \%$ to $68,1 \%$ because the produced biodiesel was not purified in order to evaluate the characteristics of the crude biodiesel produced from microalgae. The relative new technique based on a simple process is attractive for an industrial point of view. The (FAMEs) profile of the biodiesels were characterized using a GC-MS technique. The density measurements were performed over expanded ranges of pressure [0,1-140(MPa)] and temperatures [293,15(K)-353,15(K)] compatibles with their engines applications. The isothermal compressibility and the isobaric thermal expansion were estimated within the same experimental range by density differentiation. The cinematic viscosity was also measured for the three biodiesels at atmospheric pressure for temperatures ranging from 293.15 (K) to 353.15 (K). The storage stability of the biodiesels was assessed in terms of reproducibility of the measured properties. Spirulina biodiesel was not affected by oxidation process. Additionally, its density and viscosity values meet the standards specifications that support the use of this production process.
\end{abstract}

\section{Introduction}

The energy demand is continuously increasing due to the rapid development of new emergent economics. The global needs in energy are mainly supplied from fossil fuels although in the last years up to $19 \%$ of global energy demand is supplied from renewable sources, the enhancement of this percentage being a compromise of most of nations in worldwide. Both the high depletion rate of fossil fuels and the increasing emission of greenhouse gases, particularly $\mathrm{CO}_{2}$, have incited much demand for alternative and renewable fuels especially for transport $[1,2]$. Among the alternative, biodiesel is of great prominence over petro-diesel considering safety, renewability, non-toxicity, and lubricating property. In this scenario, production of algal biodiesel received much attention due to their high biomass productivity (up to $100 \mathrm{t} /$ ha.year), and lipid content (30-60\%d.wt.) [3-5], thus it being proposed to achieve lipids productivities up to $40.000-50.000 \mathrm{~L} / \mathrm{ha}-$ year [6]. Moreover, the production of lipid from microalgae have environmental advantages due to their ability to grow in contaminated waters, to sequester atmospheric $\mathrm{CO}_{2}$, and to recover nutrients from wastewaters, in addition to their capacity to be produced in non-arable land and in continuous mode with low generation time for the development of sustainable fuel. However constrains also exist due the still high production cost and uncertainty about the quality of final biodiesel produced [6].

The physical and chemical properties of algal biodiesel depend on the type of strain and culture conditions, in addition to the downstream processing, both determining the fatty methyl ester composition and finally the fuel properties [7]. Production of freshwater strains is most recommendable because the fatty acids are mainly saturated and monounsaturated whereas using marine strains the content of polyunsaturated fatty acid increases; concerning culture conditions low dilution rates allows to increase the fatty acids content of the biomass the accumulation of saponifiable fatty acids increasing [8]. Different strategies has been proposed to produce biodiesel from microalgae, the most promising being the direct transesterification of biomass [9]. Although the thermophysical properties of biodiesel produced from a

\footnotetext{
* Corresponding author.

E-mail address: david.bessieres@univ-pau.fr (D. Bessières).
} 
wide variety of natural feedstock have been largely investigated, still the studies focusing on algal biodiesel remains scarce. Most of these studies are restricted to limited pressure and temperature ranges $[10,11]$. In order to size engines and injection systems, it is relevant to assess the accurate knowledge of the thermophysical properties within pressure and temperature conditions compatibles with the operating ranges.

Among them, density and compressibility are of importance to optimize the injection process. Density is the fundamental property that influences the conversion of volume flow rate into mass biodiesel flow rate [12] whereas the compressibility linked to a bulk modulus controls the fuel injection timing [13]. Density depends upon the raw materials used for biodiesel fuel production and the biodiesel methyl ester profile [14]. The knowledge of viscosity is also an important concern to automotive manufacturers as higher viscosity values tend to alter injection spray characteristics, resulting in fuel impregnement on the chamber [15]. So, fuel which is too highly viscous can damage the fuel pump.

In this context, this study details the main features of biodiesel produced from three selected microalgae. Biomass from three largely different microorganisms were used: (i) the marine strain Nannochloropsis gaditana, (ii) the freshwater strain Scenedesmus almeriensis and (iii) the freshwater cyanobacteria Spirulina platensis. Biodiesel was obtained from the three different biomasses by direct transesterification, using the same methodology and conditions, thus the quality of final biodiesel being only a function of composition of raw material used. The produced biodiesel was not purified in order to evaluate the characteristics of the crude biodiesel produced from microalgae. Very scarce information is available about the biodiesel produced from microalgae in spite that it has been widely reported that it could be easily produced. It is a relative new and simple process with good efficiency and interest from an industrial point of view. This work aims at characterizing theses biodiesel obtained from this particular production method using the thermophysical properties as main indicators. In this sense, density measurements were carried out within extended ranges of pressure (0.1-140 (MPa)) and temperature ( $293.15 \mathrm{~K}-353,15 \mathrm{~K})$. The isothermal compressibility and the isobaric thermal expansion were derivated from the density measurements. The viscosity was also measured at atmospheric pressure on a wide temperature range $(293,15 \mathrm{~K}-353,15 \mathrm{~K})$. The reproducibility of these properties was checked for each sample thus assessing the storage stability of the microalgal biodiesel. Section 2 reports information on the materials production whereas section 3 details the experimental techniques and reports the whole results obtained for the thermophysical properties.

\section{Materials and methods}

\subsection{Microalgae biomass}

Biomass from three different microorganisms were used, the marine strain Nannochloropsis gaditana, the freshwater strain Scenedesmus almeriensis and the freshwater cyanobacteria Spirulina platensis. Biomass of Spirulina platensis was supplied by the company Biorizon (Almería, Spain) and it is produced in China using raceway reactors. Biomass of the other two microalgae was produced in industrial scale outdoor tubular photobioreactors $\left(3 \mathrm{~m}^{3}\right)$, in continuous mode at $0.30 \mathrm{l} /$ day dilution rate, on Almería (Spain) at research center Las Palmerillas from Fundación Cajamar [16]. Culture medium used was prepared on freshwater or seawater using fertilizers $\left(\mathrm{NaNO}_{3}, \mathrm{KH}_{2} \mathrm{PO}_{4}\right.$, micronutrients). The cultures were performed at $\mathrm{pH}=8.0$ by on-demand injection of $\mathrm{CO}_{2}$, and temperature was controlled below $30^{\circ} \mathrm{C}$ by passing thermostated water through a heat exchanger located inside the reactor. The biomass was daily harvested by centrifugation, then being lyophilized and stored at $-18{ }^{\circ} \mathrm{C}$. Dry biomass was used as raw material whatever the microalgae/cyanobacteria used.

\subsection{Production of biodiesel from microalgae}

The production of biodiesel from microalgae biomass is performed by direct transesterification of dry biomass, by using methanol and sulfuric acid as alcohol and catalyst respectively, under inert nitrogen atmosphere conditions. The reaction is carried out in a $5 \mathrm{~L}$ stainless steel reactor, equipped with manometer and temperature sensors, and valves for the inlet and outlet of gases. Mixing is provided by a vertical stirrer (RZR2020 Heidolph) whereas temperature is controlled by HeatOn 5-Liter block (Heidolph).

To perform the reaction the first step is to prepare the methylation mixture. For this $85 \mathrm{~mL}$ of sulfuric acid (sulfuric acid 95-98\% PRS, Panreac) is slowly added into $1700 \mathrm{~mL}$ of methanol (methanol $99.5 \%$ PRS, Panreac) under continuous stirring in the reactor, then $200 \mathrm{~g}$ of dry biomass being finally added. The second step is to perform the reaction. For this the reactor is closed, and nitrogen is inlet to create an inert atmosphere inside the air chamber, then temperature is increased up to $95^{\circ} \mathrm{C}$ and maintained at this value for one hour, pressure increasing up to 3 bar. The third step is to cool the reaction mixture up to room temperature the pressure reducing till atmospheric value.

After reaction the biodiesel is extracted from the methanolic phase using hexane. For this $1700 \mathrm{~mL}$ of hexane (hexane $95 \%$ alkanes mixture PRS, Panreac) is added to the reactor and stirred gently for $20 \mathrm{~min}$, then stirring being stopped and two phases appearing. Hexane phase is removed, then it being washed with $1700 \mathrm{~mL}$ of water. Finally hexane is removed by vacuum evaporation in a rotary evaporator at $80{ }^{\circ} \mathrm{C}$ and 20 mbar to obtain biodiesel product, which is weighted and analyzed.

\subsection{Fatty acids analysis and evaluation of yield}

The fatty acids content of whatever sample (biomass, biodiesel) is determined by gas-chromatography using flame ionization detection (GC-FID) (7683 Series Injector, 6890N Network GC system, Agilent Technologies, column Omegawax ${ }^{\mathrm{TM}} 250-$ Supelco) [17]. All the measurements are performed over fatty acids methyl esters (FAMEs), then the preparation of the sample is different according to nature of the sample. Biomass is methylated before GC-FID determination, while the biodiesel samples are only diluted in solvent and enriched with internal standard before GC-FID.

To evaluate the yield of the process different parameters are determined [18-20]. The conversion yield is determined as the ratio between the mass of FAMEs into biodiesel with respect to FAMEs from the biomass. The purity of biodiesel is determined as the ratio between the mass of FAMEs into biodiesel with respect to mass of biodiesel weighted. The FA extraction yield is determined as the ration between the total fatty acids into the biodiesel with respect to total fatty acids into the biomass. To determine the FA extraction yield it is necessary to perform an additional reaction of transesterification to biodiesel samples to ensure that no fatty acids remains as free fatty acids into the biodiesel sample. This parameter is the most relevant to evaluate the recovery of total fatty acids contained into the biomass, including if transesterification is not performed at $100 \%$ yield.

\subsection{Analysis of FAME: analytical conditions}

Fatty acid methyl esters (FAME) profile of the three biodiesel prepared from the three different microalgae Nannochloropsis, Scenedesmus and Spirulina were estimated using Thermo Scientific ${ }^{\mathrm{TM}} \mathrm{ISQ}^{\mathrm{TM}} \mathrm{LT}$ Single Quadrupole GC-MS System. The column used was Thermo Scientific ${ }^{\text {TM }}$ Trace GOLD TG-5MS with dimension $0.25 \mu \mathrm{m}$ thickness - $0.25 \mathrm{~mm}$ ID $30 \mathrm{~m}$ length). The oven temperature was initially held at $160^{\circ} \mathrm{C}$ for $2 \mathrm{~min}$, increased to $180^{\circ} \mathrm{C}$ at $2{ }^{\circ} \mathrm{C} / \mathrm{min}$ and held for $2 \mathrm{~min}$, increased continuously to $250^{\circ} \mathrm{C}$ at $10^{\circ} \mathrm{C} / \mathrm{min}$ and then help for $2 \mathrm{~min}$. The injector, transfer and source temperatures were $250{ }^{\circ} \mathrm{C}, 260^{\circ} \mathrm{C}$ and $240{ }^{\circ} \mathrm{C}$ respectively. Carrier gas was helium and total scan time $24 \mathrm{~min}$. EI mode of ionization was applied and mass scan rang was from 50 to 
$450 \mathrm{~m} / z$. GCMS solution Xcalibur software was used for data processing. For identification of FAME library search was carried out using NIST, NBS and Wiley GC-MS library.

\subsection{High pressure density and viscosity measurements}

An Anton-Paar DMA HPM high-pressure vibrating-tube densimeter was used to measure the density, $\rho$, as a function of pressure $p$ (up to $140 \mathrm{MPa}$ ) and temperature T (between 293.15 and 353.15 K). Details of the equipment and its operation have been largely described in previous studies [21]. The densimeter was calibrated with water and vacuum using the procedure described by in Ref. [22]. The estimated uncertainty of the measured temperature was $\pm 0.01 \mathrm{~K}$ between 293.15 and 353.15 K (Anton Paar MKT50 thermometer). The estimated uncertainty of the measured pressure was $\pm 0.015 \mathrm{MPa}$ (Presens Precise Gold Plus pressure transmitter) and the estimated uncertainty of the determined density was $\pm 0.5 \mathrm{~kg} \mathrm{~m}^{-3}$ (i.e., around $0.05 \%$ for density close to water density). This uncertainty is similar to that reported in several studies [23-26].

The set of viscosity measurements was taken from 278.15 to $348.15 \mathrm{~K}$ with an Ubbelohde capillary viscometer, connected to an automatic AVS350 Schott Geräte Analyzer. The temperature of the fluid was controlled within $0.05 \mathrm{~K}$ (AOIP PHP602) using a thermostatic bath. The dynamic viscosity is obtained from the product of the kinematic viscosity and the density with an uncertainty of less than $1 \%$. Each capillary tube is provided with a calibration certificate, but the calibration of the capillary viscometer was checked at several temperatures using "Viscosity Reference Standard" fluid S20 provided by ColeParmer.

\section{Results and discussion}

\subsection{Efficiency of transesterification process}

The three microorganisms selected include the most representative microalgae/cyanobacteria potentially usable to produce biodiesel. Spirulina platensis is the largest microalga/cyanobacteria produced in the world, it being mainly produced in raceway reactors using bicarbonate-rich culture mediums to avoid contamination. The lipidsfatty acids content of cyanobacteria is usually lower than microalgae (up to $12 \%$ d.wt. lipids and $6 \%$ d.wt. FA) but it can be produced easily at large scale including some of them with no nitrogen sources. Scenedesmus almeriensis is a freshwater strain tolerant to high temperature and with high growth rate, thus strains of genera Scenedesmus being the most robust and productive microalgae to be produced at large scale, including coupling with wastewater treatment [27]. The lipids-fatty acids content of Scenedesmus is moderate (up to $20 \%$ d.wt. lipids and $12 \%$ d.wt. FA) but it has the advantage of low content of polyunsaturated fatty acids, major fatty acids being palmitic and palmitoleic. Nannochloropsis gaditana is the seawater strain mostly produced in the world for aquaculture, it being one of most recommendable for biodiesel production due to its high productivity and lipids content [28]. Nannochloropsis is also a robust strain with high lipidsfatty acids content (up to $30 \%$ d.wt. lipids and $20 \%$ d.wt. FA), including higher than freshwater strains. The major disadvantage of this strain is the high percentage of polyunsaturated fatty acids, with high content of eicosapentaenoic.

To evaluate the quality of biodiesel obtained from each type of microalga/cyanobacteria, biomass of each one was subject to the biodiesel production procedure. The fatty acids content of each sample is different in addition to the fatty acids profile (Table 1). Nannochloropsis gaditana is the richest fatty acids biomass with $10.64 \%$ d.wt. whereas the fatty acids content of Spirulina platensis biomass is only of $5.03 \%$ d.wt. According to this different fatty acids content, the amount of biodiesel produced was the higher when using Nannochloropsis gaditana, up to $0.119 \mathrm{~g}_{\text {biodiesel }} / \mathrm{g}_{\text {biomass, }}$ whereas using Spirulina platensis the amount of biodiesel produced was the lower, only 0.067 g biodiesel/ $\mathrm{g}_{\text {biomass. }}$ Anyway, the amount of biodiesel obtained is larger than the fatty acids content of the biomass, thus indicating that purity of biodiesel is lower than $100 \%$ and other compounds are in mix with FAMEs. Purity of biodiesel in terms of FAMEs weight with respect to total mass of biodiesel varies from $68.1 \%$ when using biomass of $N$. gaditana to $63.7 \%$ when using biomass of $S$. platensis. This low purity percentage confirm that during extraction with hexane other compounds than FAMEs are extracted from the reaction mixture, it mainly corresponding to non saponifiable lipids that could represent up to $60 \%$ of total lipids. Regarding FA extraction yield and conversion, determined values demonstrates as the process used for the extraction and transesterification of fatty acids from the biomass is highly efficient. Thus, the recovery of FA from the biomass into the biodiesel fraction ranges from 88.9 to $97.9 \%$, whereas the conversion fraction varies from 84.3 to $92.7 \%$. According to these results less than a $10 \%$ of fatty acids are non-extracted from the biomass, and only less than a $5 \%$ of extracted fatty acids remain as free fatty acids into the biodiesel phase.

Direct transesterification of microalgae biomass has been proposed as an alternative for the production of biodiesel without the necessity of oil extraction from the biomass. In addition this reaction can be performed using wet biomass instead of dry biomass, thus also avoiding the necessity of evaporating water and improving the energy balance of the entire system [18]. Methodology here used demonstrate to be useful to extract and convert fatty acids from microalgae biomass recovery efficiencies from 88.9 to $97.9 \%$ and conversion values from 84.3 to $92.7 \%$ being obtained. These values are higher the higher the fatty acids content of the biomass thus the utilization of biomass with highest as possible fatty acids content is recommended. However, the purity of biodiesel obtained is low, with values ranging from 63.7 to $68.1 \%$ - and is out of accordance with standard values for commercial biodiesel (ASTM D6751 and EN 14214) regarding FAME percentage. This result was expected considering we used a relatively new technique that gives a less pure product but with the advantage of being a more simple process with a higher efficiency. The fact there is no need of a previous drying process makes it very attractive for an industrial point of view.

Here, it should be considered that the study of this not-so-pure biodiesel obtained by this particular method provides information for the improvement of the process. Regarding the standards, the objective of this study is to know how far this biodiesel was from the standards values and how this affected (or not) its performance.

Hexane is used to extract FAMEs from the reaction mixture, thus other organic compounds can be also extracted to biodiesel phase in addition to FAMEs that reduces the purity of biodiesel obtained. To increase this purity the implementation of refining steps is mandatory. In any case data here reported agree with reported by Haas and Wagner [19], that obtain conversions from $80 \%$ to $98 \%$ at lower temperatures but higher reaction times. Similar values are reported by Ehimen et al. [20], that analyzed the effect of the temperature at different reaction times, concluding that increase of temperature only reduces the time requested to achieve maximal conversion, but maximal conversion ranges from 85 to $98 \%$.

\subsection{Analysis of FAME profiles}

Many properties of algal biodiesel are determined by their fatty acid profiles. Technical problems such as poor cold flow properties or oxidative stability can be traced to the individual component of the fatty acid profile. In this sense, all the samples were analyzed by GC-MS quadrupole and the composition of fatty acid methyl esters was identified as follows. The individual peaks of the gas chromatogram were analyzed and the components were identified using MS database. Relative percentage of fatty acid esters was calculated from total ion chromatography by computerized integrator. The results are presented in the Table 2 for three algae biodiesel prepared with Nannochloropsis gaditana, Spirulina platensis and Scenedesmus almeriensis. The palmitic 
Table 1

Conversion and purity of biodiesel obtained from strain Nannochloropsis gaditana, Scenedesmus almeriensis and Spirulina platensis.

\begin{tabular}{|c|c|c|c|c|c|}
\hline Biomass & FA content, \%d.wt. & Biodiesel, $g_{\text {biodiesel }} / g_{\text {biomass }}$ & Purity,\% & Extraction yield, \% & Conversion, $\%$ \\
\hline Nannochloropsis gaditana & 10.64 & 0.119 & 68.1 & 97.9 & 92.7 \\
\hline Scenedesmus almeriensis & 6.03 & 0.084 & 64.6 & 92.6 & 90.3 \\
\hline Spirulina platensis & 5.03 & 0.067 & 63.7 & 88.9 & 84.3 \\
\hline
\end{tabular}

Table 2

Fatty acid profile of biodiesel from three strain of microalgae: Nannochloropsis gaditana, Scenedesmus almeriensis and Spirulina platensis.

\begin{tabular}{|c|c|c|c|}
\hline \multirow[t]{2}{*}{ FAME } & $\begin{array}{l}\text { Nannochloropsis } \\
\text { gaditana }\end{array}$ & $\begin{array}{l}\text { Spirulina } \\
\text { platensis }\end{array}$ & $\begin{array}{l}\text { Scenedesmus } \\
\text { Almeriensis }\end{array}$ \\
\hline & \%wt & & \\
\hline $\begin{array}{l}\text { Methyl tetradecanoate } \\
\text { (C14:0) }\end{array}$ & 5.61 & 4.38 & 0.48 \\
\hline $\begin{array}{l}\text { Methyl } \\
\text { hexadecatetraenoate } \\
\text { (C16:4) }\end{array}$ & & & 2.65 \\
\hline $\begin{array}{l}\text { Methyl hexadecatrienoate } \\
\text { (C16:3) }\end{array}$ & & & 6.35 \\
\hline Methyl palmioleate (C16:1) & 29.91 & 8.44 & 2.04 \\
\hline Methyl palmitate (C16:0) & 32.71 & 42.25 & 47.12 \\
\hline Methyl linolenate (C18:3) & & 13.82 & 28.55 \\
\hline Methyl linoleate (C18:2) & 3.74 & 21.93 & 7.9 \\
\hline Methyl oleate (C18:1) & 7.48 & 1.75 & 2.4 \\
\hline Methyl stearate (C18:0) & & 2.52 & 0.64 \\
\hline $\begin{array}{l}\text { Methyl arachidonate } \\
\text { (C20:4) }\end{array}$ & 3.27 & & \\
\hline $\begin{array}{l}\text { Methyl eicosapentaenoate } \\
\text { (C20:5) }\end{array}$ & 15.42 & & \\
\hline
\end{tabular}

acid and palmitoleic acid are the major fatty acids in Nannochloropsis microalgae, followed by eicosapentaenoic acid and oleic acid. Tetradecanoic, linoleic and arachidic acids are present as minor constituents. This result is in conformity with the result investigated by $\mathrm{Hu}$ and Gao [29] and Xu et al. [30]. Because of containing a significant percentage of methyl eicosapentaenoate (C20:5), a component with very high rate of oxidation, a low oxidative stability is expected for biodiesel prepared from Nannochloropsis microalgae.

For Spirulina platensis, the observed fatty acid profile exhibits a very high amount of palmitic acid (42.25 wt\%), which indicates that biodiesel from this strain would likely have poor cold properties [31-32]. The analysis of the FAME profile for Scenedesmus almeriensis biodiesel confirms that palmitic acid is the most common component observed in algal oils (here $47.12 \%$ ). The most feature is the abundant presence of Methyl Linolenate (18:3), which is also susceptible to oxidation in the classification proposed by Frankel et al. [33].

\subsection{Thermophysical properties as indicator of the storage stability}

When performing the experimental measurements, a similar procedure was applied for each sample which consists in measuring the reproducibility or the change on its properties. The first objective was to assess the reliability of the determined thermophysical properties of algal biodiesel knowing the technical problems linked with oxidation stability or solid content deposition. Similarly, this is an attempt to provide information on long term storage properties of bio crude obtained from algal biomass.

Concerning the density measurements, a good reproducibility was observed for all the samples during the first set of measurement. When reproducing the experiments by one month intervals, significant deviation appear both for Nannochloropsis and Scenedesmus with still increasing values. The densities values show deviations $(0,6 \%)$ largely superior to the permitted uncertainty $(0,05 \%)$. This evolution on the density was correlated to the low oxidative stability of some components found in their FAME profiles. In the case of Nannochloropsis, the presence in abundance of methyl eicosapentaenoate (C20:5) is susceptible to oxidation whereas Methyl Linolenate (18:3), reported in the FAME profile of Scenedesmus, also presents a significant rate of oxidation. In the case of the biodiesel obtained from Spirulina, a good reproducibility was found, with deviations always within the uncertainty range, when measuring the values at one month interval.

As for density, little information is available for viscosity of biodiesel obtained from algae biomass. On their work devoted to a bio crude generated from Spirulina, Jena et al. [11] reports a linear increase in viscosity during storage. This phenomenon is defined as aging. The rapid increase in viscosity of algal bio crude during the initial phase is assimilated to loss of volatiles or chemical reactions of oxygenated compounds or a combination of the two above. In this study the pattern of viscosity change for Nannochloropsis presents similarities with a rapid increase on the initial phase. Fig. 1 displays the changes observed for viscosities at $20^{\circ} \mathrm{C}$ and $0,1(\mathrm{MPa})$. This behavior should be correlated either to the volatility of any compounds or more probably to its low oxidative stability [31-33]. However, a very good reproducibility on the viscosity values was found both for Spirulina and Scenedesmus. The values were not affected as well by storage behavior during various days. As a consequence, we'll report here the whole thermophysical data for Spirulina knowing their reliability and their transferability for engines uses. We'll recall here that Spirulina biomass has the low content of fatty acids 5,03\% d.wt.

\subsection{Results for Spirulina platensis biodiesel}

\subsubsection{Density measurements}

Density measurements were carried out along isotherms spaced at $20 \mathrm{~K}$ interval (from 293,15 to $353,15 \mathrm{~K}$ ) in the pressure range (0.1-140 MPa) by steps of $10 \mathrm{MPa}$. At lower temperatures - 273,15 Kmeasurements were limited by the appearances of solid deposition at pressures higher than $50 \mathrm{MPa}$. The relative poor cold properties of Spirulina is due to the significant amount of palmitic acid $(42,25 \%)$. This is a limitation to be considered for its engines use. As it can be observed in Fig. 2, the density exhibits a classical behavior. The effect of

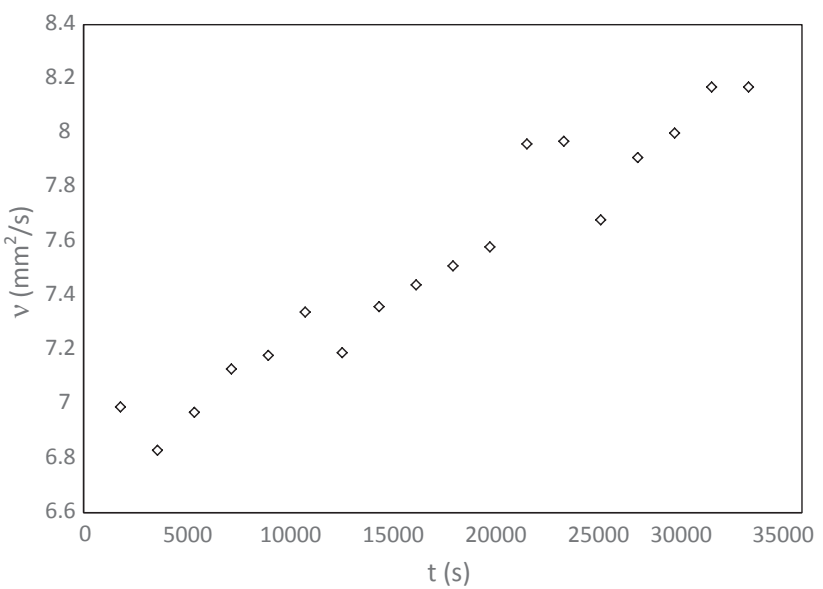

Fig. 1. Evolution of the Cinematic Viscosity of Nannochloropsis $\left(20^{\circ} \mathrm{C}, 0,1 \mathrm{MPa}\right)$ as a function of time. 


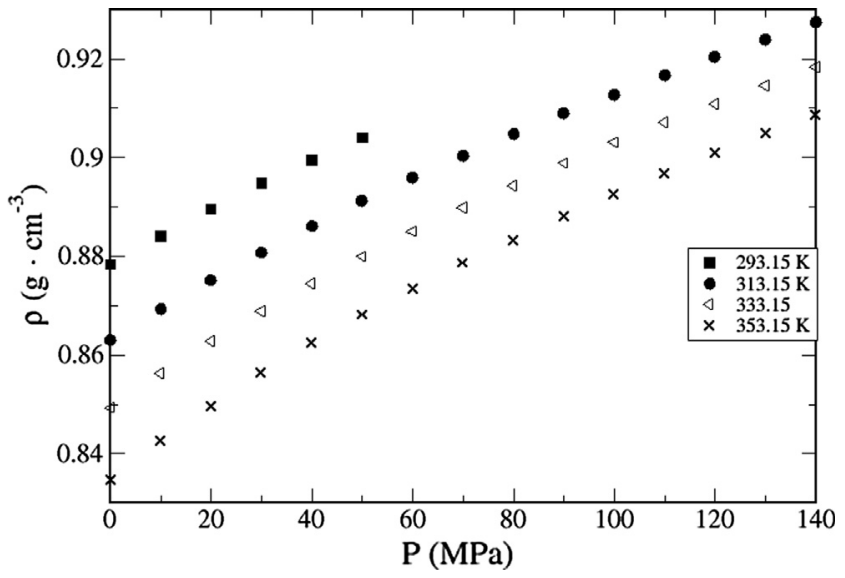

Fig. 2. Density $\rho\left(\mathrm{g} . \mathrm{cm}^{-1}\right)$ of Spirulina biodiesel as a function of pressure (isothermal curves).

Table 3

Density data $\rho\left(\mathrm{g} . \mathrm{cm}^{-3}\right)$ of Spirulina Platensis.

\begin{tabular}{|c|c|c|c|c|}
\hline \multirow[t]{3}{*}{$\mathrm{p} / \mathrm{MPa}$} & \multicolumn{4}{|l|}{$\mathrm{T} / \mathrm{K}$} \\
\hline & 293.15 & 313.15 & 333.15 & 353.15 \\
\hline & \multicolumn{4}{|c|}{$\rho\left(\mathrm{g} \cdot \mathrm{cm}^{-3}\right)$} \\
\hline 0.1 & 0.8783 & 0.8631 & 0.8493 & 0.8347 \\
\hline 10 & 0.8841 & 0.8693 & 0.8562 & 0.8425 \\
\hline 20 & 0.8896 & 0.8752 & 0.8627 & 0.8496 \\
\hline 30 & 0.8948 & 0.8808 & 0.8688 & 0.8562 \\
\hline 40 & 0.8995 & 0.8862 & 0.8744 & 0.8623 \\
\hline 50 & 0.9040 & 0.8912 & 0.8799 & 0.8681 \\
\hline 60 & & 0.8959 & 0.8850 & 0.8734 \\
\hline 70 & & 0.9003 & 0.8898 & 0.8786 \\
\hline 80 & & 0.9048 & 0.8943 & 0.8832 \\
\hline 90 & & 0.9089 & 0.8988 & 0.8880 \\
\hline 100 & & 0.9127 & 0.9030 & 0.8924 \\
\hline 110 & & 0.9166 & 0.9071 & 0.8966 \\
\hline 120 & & 0.9204 & 0.9109 & 0.9008 \\
\hline 130 & & 0.9239 & 0.9146 & 0.9049 \\
\hline 140 & & 0.9274 & 0.9182 & 0.9086 \\
\hline
\end{tabular}

Table 4

Parameters of the Tait-like Eq. (1).

\begin{tabular}{ll}
\hline Coefficients & Biodiesel \\
\hline$A_{0} /\left(\mathrm{g} \cdot \mathrm{cm}^{-3}\right)$ & 1,09176 \\
$A_{1} /\left(\mathrm{g} \cdot \mathrm{cm}^{-3} \cdot \mathrm{K}^{-1}\right)$ & $-0,00072824$ \\
$B_{0} /(\mathrm{MPa})$ & 599,936 \\
$B_{1} /\left(\mathrm{MPa} \cdot \mathrm{K}^{-1}\right)$ & $-2,371473$ \\
$B_{2} /\left(\mathrm{MPa} \cdot \mathrm{K}^{-2}\right)$ & $2,602 \mathrm{E}-03$ \\
$C$ & 0,0850530 \\
$\sigma /\left(\mathrm{g} \cdot \mathrm{cm}^{-3}\right)$ & 0.000152 \\
$\mathrm{AAD} /(\%)$ & 0.012682 \\
\hline
\end{tabular}

pressure can be assumed to a linear increase while the density is decreasing with temperature. Any singularities Troncoso et al. [34] due to the presence of oxygenated compounds was observed in a behavior similar to those observed for petrodiesel. The density measured at $15^{\circ} \mathrm{C}$ and at the atmospheric pressure is $0,882 \mathrm{~g} \cdot \mathrm{cm}^{-3}$. Its value is an agreement with the specifications of the EN 1424. The raw data are listed in Table 3 . In order to better correlate the density, we use a modified Taitlike equation. Parameters are plotted in the Table 4.

$\rho(P, T)=\left(\frac{\rho_{0}(T)}{1-C \ln \frac{P+B(T)}{0,1+B(T)}}\right)_{p}$

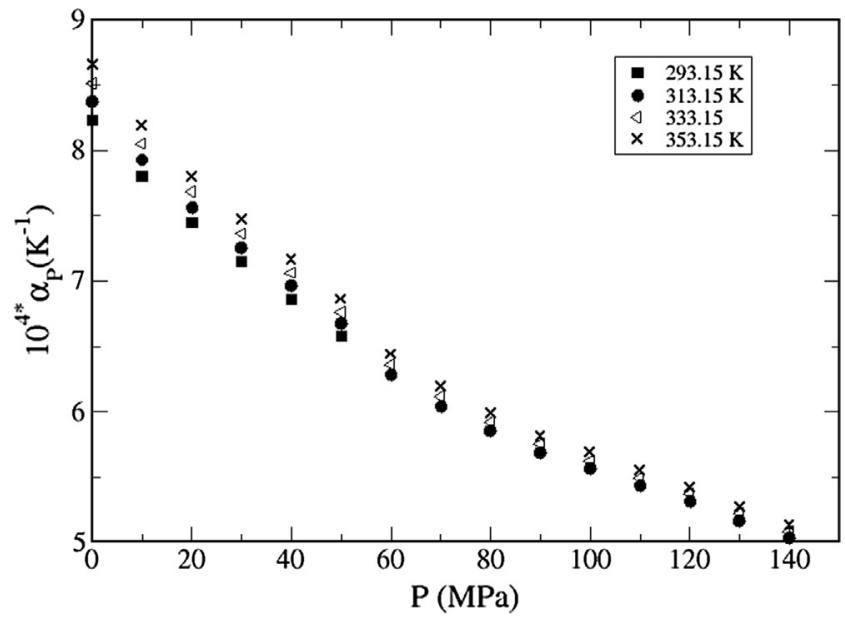

Fig. 3. Isobaric Thermal Expansion of $10^{4} * \alpha_{\mathrm{p}}\left(\mathrm{K}^{-1}\right)$ of Spirulina Platensis as a function of pressure (isothermal curves).

where

$\rho_{0}(T)=A_{0}+A_{1} T$

$B(T)=B_{0}+B_{1} T+B_{2} T^{2}$

\subsubsection{Derived thermodynamic properties}

The derived thermodynamic properties were estimated by analytical differentiation of Eq. (1) versus pressure and temperature. The isobaric thermal expansion coefficient at constant pressure $\alpha_{\mathrm{P}}$ is defined as:

$\alpha_{P}=-\frac{1}{\rho}\left(\frac{d \rho}{d T}\right)_{p}$

while the isothermal compressibility is defined as:

$\varkappa_{T}=\frac{1}{\rho}\left(\frac{d \rho}{d P}\right)_{T}$

As indicated on similar high-pressure density studies Troncoso et al. $[34,35]$ with the same methods, the estimated uncertainty is $1 \%$ for the isothermal compressibility, and around 3\% for the isobaric thermal expansivity. As an illustration, Fig. 3 shows the variation of $\alpha_{p}$ as a function of pressure and Fig. 4 shows the variation of $\kappa_{T}$ as a function of temperature for several isobars. This set of data represents meaningful information and support the use of this technique of production. From a theoretical point of view, the isobaric thermal expansion behavior of liquids and liquid mixtures exhibits a cross-over point between the

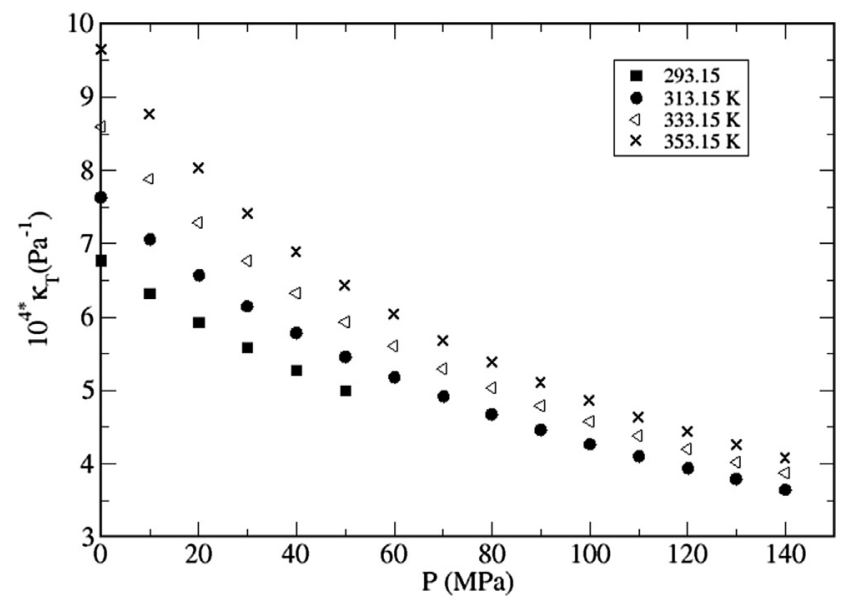

Fig. 4. Isothermal compressibility $10^{4} * \kappa_{\mathrm{T}}\left(\mathrm{Pa}^{-1}\right)$ of Spirulina Platensis as a function of pressure. 
Table 5

Isobaric Thermal expansion coefficient $\alpha_{\mathrm{P}}$ (K-1) of Spirulina Platensis biodiesel.

\begin{tabular}{lllll}
\hline & \multicolumn{1}{l}{$\mathrm{T} / \mathrm{K}$} & & \\
\cline { 2 - 5 } & 293.15 & 313.15 & 333.15 & 353.15 \\
\cline { 2 - 5 } $\mathrm{p} / \mathrm{MPa}$ & $10^{4} * \alpha_{\mathrm{P}} / \mathrm{K}^{-1}$ & & & \\
\hline 0.1 & 8.23 & 8.37 & 8.51 & 8.66 \\
10 & 7.80 & 7.93 & 8.05 & 8.19 \\
20 & 7.45 & 7.56 & 7.68 & 7.80 \\
30 & 7.15 & 7.25 & 7.36 & 7.47 \\
40 & 6.86 & 6.96 & 7.06 & 7.16 \\
50 & 6.58 & 6.67 & 6.76 & 6.86 \\
60 & & 6.28 & 6.36 & 6.44 \\
70 & & 6.04 & 6.11 & 6.19 \\
80 & & 5.85 & 5.92 & 5.99 \\
90 & & 5.68 & 5.75 & 5.81 \\
100 & & 5.56 & 5.62 & 5.69 \\
110 & & 5.43 & 5.49 & 5.55 \\
120 & & 5.31 & 5.37 & 5.42 \\
130 & & 5.16 & 5.22 & 5.27 \\
140 & & 5.03 & 5.08 & 5.13 \\
\hline
\end{tabular}

Table 6

Isothermal compressibility $\kappa_{\mathrm{T}}\left(\mathrm{Pa}^{-1}\right)$ of Spirulina Platensis biodiesel.

\begin{tabular}{lllll}
\hline & \multicolumn{1}{l}{$\mathrm{T} / \mathrm{K}$} & & \\
\cline { 2 - 5 } & 293.15 & 313.15 & 333.15 & 353.15 \\
\cline { 2 - 5 } $\mathrm{p} / \mathrm{MPa}$ & $10^{4 *} \kappa_{\mathrm{T}} / \mathrm{Pa}^{-1}$ & & & \\
\hline 0.1 & 6.77 & 7.63 & 8.59 & 9.65 \\
10 & 6.32 & 7.06 & 7.88 & 8.77 \\
20 & 5.93 & 6.57 & 7.28 & 8.03 \\
30 & 5.58 & 6.15 & 6.76 & 7.41 \\
40 & 5.27 & 5.78 & 6.32 & 6.88 \\
50 & 5.00 & 5.46 & 5.93 & 6.43 \\
60 & & 5.17 & 5.60 & 6.03 \\
70 & & 4.91 & 5.29 & 5.68 \\
80 & & 4.67 & 5.03 & 5.38 \\
90 & & 4.46 & 4.78 & 5.10 \\
100 & & 4.27 & 4.57 & 4.86 \\
110 & & 4.10 & 4.37 & 4.63 \\
120 & & 3.94 & 4.19 & 4.43 \\
130 & & 3.79 & 4.02 & 4.25 \\
140 & & 3.65 & 3.87 & 4.08 \\
\hline
\end{tabular}

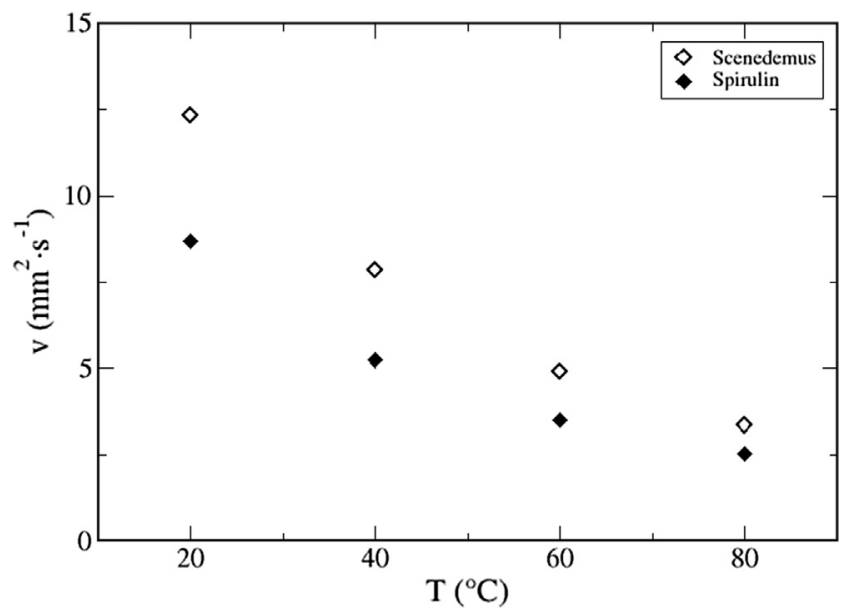

Fig. 5. Cinematic viscosity of Spirulina Platensis and Scenedesmus as a function of temperature (atmospheric pressure).

isotherms at a given pressure. This cross-over doesn't appear in the covered experimental range. The trend observed suggests that this singularity is moved towards higher pressure. This is probably due to the presence of oxygenated compounds (26) in the algal biodiesel. The raw data are provided in Tables 5 and 6.

\subsubsection{Viscosity measurements}

The measurements of viscosity for Spirulina have been performed at the atmospheric pressure for temperatures ranging from $293,15(\mathrm{~K})$ to $353,15(\mathrm{~K})$. Fig. 5 shows the variation of viscosity as a function of temperature. As usual, viscosity decreases drastically as temperature. Its value $5,2452 \mathrm{~mm}^{2} / \mathrm{s}$ measured at $40{ }^{\circ} \mathrm{C}$ and 1 bar is clearly within the authorized range by EN14124. Despite its low purity $(63,7 \%)$, the Spirulina platensis delivers a biodiesel compliant with both transport and volumetric standards recommended for biodiesel which is a very promising result.

\subsection{Results for Scenedesmus}

In the case of the biodiesel produce from Scenedesmus, we only report the viscosity measurement (see Fig. 5). The measurements have been performed at the atmospheric pressure for temperatures ranging from $293.15(\mathrm{~K})$ to 353.15 (K). As already mentioned, a good reproducibility was observed. However, the value reported at $40{ }^{\circ} \mathrm{C}$ $7.8417 \mathrm{~mm}^{2} / \mathrm{s}$ is higher to those recommended for biodiesel mainly due to its low purity. This result suggests the difficulty to transfer this biodiesel at the industrial scale.

\section{Conclusions}

Density and viscosity of three microalgae biodiesel (Nannochloropsis salina, Spirulina Platensis and Scenedesmus) were experimentally investigated over broad ranges of pressure and temperature. To the best of our knowledge, this is the first set of experimental data provided for algal biodiesel in pressure and temperature ranges.

The main conclusions can be depicted as follows:

- Algal biodiesels were directly produced from the biomass through the use of a relatively new technique that gives a less pure product but with the advantage of being a more simple process with a higher efficiency. The fact there is no need of a previous drying process makes it very attractive for an industrial point of view.

- A poor stability was observed for both the biodiesel obtained from Nannochloropsis salina and Scenedesmus. This is due their FAME profile.

- The biodiesel obtained from Spirulina biomass has demonstrated high stability. Additionally, the density and viscosity values of Spirulina biodiesel support its transferability, keeping in mind the purity should be improved.

- The original set of experimental data measured for Spirulina could be used to test predictive models developed for biodiesel thermodynamic properties.

\section{References}

[1] Mathimani T, Kumar TS, Chandrasekar M, Uma L, Prabaharan D. Assessment of fuel properties, engine performance and emission characteristics of outdoor grown marine Chlorella vulgaris BDUG 91771 biodiesel. Renewable Energy 2017;105:637-46.

[2] Gutiérrez-Arnillas E, Álvarez MS, Deive FJ, Rodríguez A, Sanromán MA. New horizons in the enzymatic production of biodiesel using neoteric solvents. Renewable Energy 2016;98:92-100.

[3] Albuquerque CG, Machado YL, Torres AEB, Azevedo DCS, Cavalcante CL, Firmiano LR, et al. Properties of biodiesel oils formulated using different biomass sources and their blends. Renewable Energy 2009;34:857-9.

[4] Mata T, Martins A, Caetano N. Microalgae for biodiesel production and other applications. A review. Renew Sust Energy Rev 2010;14:217-32.

[5] Demirbas MF. Biofuels from algae for sustainable development. Appl Energy 2011;88:3473-80.

[6] Chisti Y. Constraints to commercialization of algal fuels. J Biotechnol 2013;167(3):201-14.

[7] Wileman A, Ozkan A, Berberoglu H. Rheological properties of algae slurries for minimizing harvesting energy requirements in biofuel production. Bioresour 
Technol 2012;104:432-9.

[8] Robles Medina A, Molina Grima E, Giménez Giménez A, Ibáñez González MJ. Downstream processing of algal polyunsaturated fatty acids. Biotechnol Adv 1998;16(3):517-80.

[9] Grima EM, Fernández FGA, Medina AR. Downstream processing of cell-mass and products 2005; Ch10 in book: handbook of microalgal culture: biotechnology and applied phycology, 215-252.

[10] Schneider N, Fortin TJ, Span R, Gerber M. Thermophysical properties of the marine microalgae Nannochloropsis Salina. Fuel Process Technol 2016:152:390-8.

[11] Jena U, Das UKC, Kastner JR. Effect of operating conditions of thermochemical liquefaction on biocrude production from Spirulina platensis. Bioresour Technol 2011;102:6221-9.

[12] Veny H, Baroutian S, Aroua M, Hasan M, Raman A, Sulaiman N. Density of Jatropha curcas seed oil and its methyl esters: measurement and estimations. Int J Thermophys 2009;30:529-41.

[13] Noureddini H, Teoh B, Clements L. Densities of vegetable oils and fatty acids. J Am Oil Chem Soc 1992;69(12):1184-8.

[14] Ndiaye EAI, Bazile J-P, Nasri D, Boned C, Daridon J-L. High pressure thermophysical characterization of fuel used for testing and calibrating diesel injections systems. Fuel 2012;98:288-94.

[15] Dzida M, Prusakiewicz P. The effect of temperature and pressure on the physicochemical properties of petroleum diesel oil and biodiesel fuel. Fuel 2008;87:1941-8.

[16] Fernández I, Acién FG, Fernández JM, Guzmán JL, Magán JJ, Berenguel. Dynamic model of microalgal production in tubular photobioreactors. Bioresour Techno 2012;126:172-81.

[17] Rodríguez-Ruiz J, Belarbi E, García J, López D. Rapid simultaneous lipid extraction and transesterification for fatty acid analyses. Biotechnol Tech 1998;12:689-91.

[18] Belarbi EH, Molina E, Chisty Y. A process for high yield and scaleable recovery of high purity eicosapentaenoic acid esters from microalgae and fish oil. Enzyme Microb Technol 2000;26:516-29.

[19] Haas MJ, Wagner K. Simplifying biodiesel production: the direct or in situ transesterification of algal biomass. Eur J Lipid Sci Technol 2011;113:1219-29.

[20] Ehimen EA, Sun ZF, Carrington CG. Variables affecting the in situ transesterification of microalgae lipids. Fuel 2010;89:677-84.

[21] Pineiro MM, Bessieres D, Gacio JM, Saint-Guirons H, Legido JL. Determination of high-pressure liquid density for n-perfluorohexane and n-perfluorononane. Fluid Phase Equilib 2004;220(1):127-36.
[22] Lagourette B, Boned C, Saint-Guirons H, Xans P, Zhou H. Densimeter calibration method versus temperature and pressure. Measur Sci Technol 1992;3:699-703.

[23] Zéberg-Mikkelsen CK, Andersen SI. Density measurements under pressure for the binary system 1-propanol + toluene. J Chem Eng Data 2005;50(2):524-8.

[24] Milhet M, Baylaucq, Boned C. Volumetric Properties of 1-phenyldecane and 1phenylundecane at pressures to $65 \mathrm{MPa}$ and temperature between 293.15 and 353.15 K. J Chem Eng Data 2005;50(4):1430-3.

[25] Miyake Y, Baylaucq A, Plantier F, Bessières D, Ushiki H, Boned C. High-Pressure (up to $140 \mathrm{MPa}$ ) density and derivative properties of some amines (pentyl, hexyl- and heptyl-amines) between 293.15 and 353.15 K. J Chem Thermodyn 2008;40(5):836.

[26] Comunas MJP, Fernández J, Baylaucq A, Canet X, Boned C. P Tx measurements for HFC-134a + triethylene glycol dimethylether system. Fluid Phase Equilib 2002;199(1-2):185-95.

[27] Morales-Amaral MM, Gómez-serrano C, Acién FG, Fernández-sevilla JM. Production of microalgae using centrate from anaerobic digestion as the nutrient source. Algal 2015;9:297-305.

[28] Moazami N, Ashori A, Ranjbar R, Tangestani M, Eghtesadi R, Nejad AS. Large-scale biodiesel production using microalgae biomass of Nannochloropsis. Biomass Bioenergy 2012;39:449-53.

[29] $\mathrm{Hu} \mathrm{H}$, Gao K. Optimization of growth and fatty acid composition of a unicellular marine picoplankton, Nannochloropsis sp., with enriched carbon sources. Biotechnol Lett 2003;25:421-5.

[30] Xu F, Zu C, Cong W, Ouyang F. Growth and fatty acid composition of Nannochloropsissp. Grown mixotrophically in fed-batch culture. Biotechnol Lett 2004;26:1319-22.

[31] Knothe G, Steidley KR. Kinematic viscosity of biodiesel fuel components and relative compounds. Influence of compound structure and comparison to petrodiese fuel components. Fuel 2005;84:1059-65.

[32] Knothe G, Van Gerpen J, Krahl J. The biodiesel handbook. 2nd Edition Chapter 6fuel properties Urbana: AOCS Press978-1-893997-62-2; 2010.

[33] Frankel EN. Lipid oxidation, 2nd edition. Bridgewater: The Oily press/PJ Barnes and Associates; 2005.

[34] Troncoso J, Bessieres D, Cerdeirina CA, Carballo E, Romani L. Automated measuring device of ( $\mathrm{p}$, rho, T) data-Application to the 1-hexanol plus n-hexane system. Fluid Phase Equilib 2003;208(1-2):241-54.

[35] Troncoso J, Bessieres D, Cerdeirina CA, Carballo E, Romani L. P rho Tx data for the dimethyl carbonate plus decane system. J Chem Eng Data 2004;49(4):923-7. 